\title{
Interdecadal variations of pan-evaporation at the southern and northern slopes of the Tianshan Mountains, China
}

\author{
LI Sisi ${ }^{1,2,3}$, WANG Quan ${ }^{4}$, LI Lanhai ${ }^{1,3^{*}}$ \\ ${ }^{1}$ State Key Laboratory of Desert and Oasis Ecology, Xinjiang Institute of Ecology and Geography, Chinese Academy of \\ Sciences, Urumqi 830011, China; \\ ${ }^{2}$ University of Chinese Academy of Sciences, Beijing 100049, China; \\ ${ }^{3}$ Xinjiang Key Laboratory of Water Cycle and Utilization in Arid Zone, Xinjiang Institute of Ecology and Geography, Chinese \\ Academy of Sciences, Urumqi 830011, China; \\ ${ }^{4}$ Faculty of Agriculture, Shizuoka University, Shizuoka 422-8529, Japan
}

\begin{abstract}
Evaporation controlled by meteorological parameters plays a crucial role in hydrology, meteorology and water resources management. An insight view of long-term variation in evaporation will help understanding the effects of climate change and provide useful information for rational utilization of water resources, especially in the arid land where the shortage of water resources exists. However, the lack of data on evaporation led to difficulties in assessing the impacts of climate change on evaporation, especially in arid mountainous area. This study investigated the long-term variation of the pan-evaporation (Ep) measured by E601 type evaporation pan and its influencing climatic factors at both northern and southern slopes of the Tianshan Mountains in Xinjiang of China using the ensemble empirical mode decomposition method and Path analysis. The results revealed that Eps at both northern and southern slopes had obvious interdecadal variation within cycles of 3-4 and 7-8 years. Eps at both slopes sharply decreased in early 1980s, but increased after late 1990s. Path analysis showed that the 3-4 years cycle of Ep at the northern and southern slopes was mainly dependent upon actual water vapor pressure with a negative direct path coefficient of -0.515 and sunshine duration with a positive direct path coefficient of 0.370 , respectively. The variation of Ep with cycle of 7-8 years at the northern slope was attributed to the wind speed with a direct path coefficient of 0.774 . Average temperature had a direct path coefficient of 0.813 in 7-8 years cycle at the southern slope. The assessment of Ep variation and its causes provides information essential for a good understanding of hydrologic cycle and regional climate of arid mountainous regions in Xinjiang of China and offers a theoretical reference for distribution and utilization of water resources.
\end{abstract}

Keywords: interdecadal variation; pan-evaporation; Ensemble Empirical Mode Decomposition; path analysis; Tianshan Mountains

Citation: LI Sisi, WANG Quan, LI Lanhai. 2016. Interdecadal variations of pan-evaporation at the southern and northern slopes of the Tianshan Mountains, China. Journal of Arid Land, 8(6): 832-845. doi: 10.1007/s40333-016-0018-7

As an essential process in the water cycle, evaporation influences local and/or regional climate as well as water resources. It is of a great importance to investigate evaporation process due to its key role in hydrology, meteorology and agriculture. Evaporation flux in a given region depends upon meteorological factors, such as temperature, humidity, sunshine duration, wind speed, etc.

*Corresponding author: LI Lanhai (E-mail: 1ilh@ms.xjb.ac.cn)

Received 2016-02-27; revised 2016-05-20; accepted 2016-05-28

(C) Xinjiang Institute of Ecology and Geography, Chinese Academy of Sciences, Science Press and Springer-Verlag Berlin Heidelberg 2016 
Evaporation plays a substantial role in evaluating the water balance and surface energy exchange. Long term variation of pan-evaporation (Ep) implies the trend of regional climate change and the characteristics of hydrologic cycle. An insight view on Ep variation helps to understand the nature of regional climate change and provides useful information for rational utilization of water resources.

Considerable literature emphasized on the trends of Ep and the relations between Ep and its influencing factors. Under the context of global warming, Ep was expected to increase as the temperature rises, but contrary results were also observed in some regions (Chattopadhyay and Hulme, 1997; Lawrimore and Peterson, 2000; Thomas, 2000; Hoffman et al., 2001; Liu et al., 2004; Roderick and Farquhar, 2004; Chen et al., 2005; Roderick and Farquhar, 2005; Liu et al., 2009; Yang and Yang, 2012; Li et al., 2013; Zhang et al., 2015). The decrease in Ep was explained as the "Evaporation Paradox" phenomenon (Peterson, 1995), which resulted in a wide debate on the relation between evaporation and climate change. Roderick et al. (2009) and Van Heerwaarden et al. (2010) stated that decrease in wind speed contributed to the decrease in Ep, while Peterson (1995) and Roderick and Farquhar (2002) highlighted that the cutting down in Ep resulted from the decrease in solar irradiation. Brutsaert and Parlange (1998) and Hobbins et al. (2004) proposed the "Evaporation Complementary" theory to explain the contrary change trends of Ep and actual evaporation, i.e. an increase in actual evaporation would enhance the water vapor content in the air, which, in turn, inhibits Ep. As main climatic factors, temperature, humidity, sunshine duration and wind speed directly influence the evaporation; multiple linear regression analysis, variance analysis and correlation analysis have been widely used to analyze the influence of climatic factors on the evaporation. However, there exist interactive influences of climatic factors through different indirect paths. For example, temperature directly affects evaporation rate, but also indirectly impacts it through interactions with humidity, sunshine duration and wind speed. Conventional statistical methods can identify the influence of a single factor on evaporation, but they cannot quantitatively differentiate the direct and indirect influences of climatic factors on the evaporation and their influencing paths. Therefore, the challenge still remains in investigating the trend of evaporation change among different regions under climate change and the influencing intensity and paths of meteorological factors on evaporation.

Ep was traditionally measured with $20-\mathrm{cm}$ pans, but the measurements using $20-\mathrm{cm}$ pans could not completely reflect local climate due to its installation and structure features, which resulted in inaccurate evaporation data (Liu et al., 1998; Huang, 2000; Sheng et al., 2007). Instead of 20-cm pans, E601 type evaporation pans were installed for measuring the evaporation in the last few decades due to its accuracy in measuring data approximating actual evaporation (Ji and Zhou, 2011). However, E601 type evaporation pans were set up in some meteorological stations with short records, which led to difficulties in fully understanding the variation of regional hydrological cycle and climate. In order to accurately evaluate regional evaporation patterns, it was suggested to use available alternative evaporation data to reconstruct the evaporation data for the E601 type evaporation pans (Ep $\left.\mathrm{E}_{\mathrm{E} 01}\right)$. Xiong et al. (2012) estimated the E601 evaporation data by using partial least squares on the basis of data using $20-\mathrm{cm}$ pans. Some studies calculated the conversion coefficients of Ep measured by a $20-\mathrm{cm}$ pan and Ep measured by the Ep $\mathrm{E}_{601}$ (Jia et al., 2009; Jin, 2009; Aydaraili and Huang, 2011; Wei and Liu, 2011). All these provide a basis for making a full use of the long series of Ep measured by a $20-\mathrm{cm}$ pan. As an alternative method, back-propagation artificial neural network (BPANN) has been proposed to supplement the Ep $\mathrm{E}_{\mathrm{E} 001}$ because the BPANN has the abilities of self-learning and effectively solving problems.

Located in northwestern China, Xinjiang is a typical arid and semi-arid region. The Tianshan Mountains extend from east to west and divide Xinjiang into two parts, i.e. South Xinjiang and North Xinjiang. The mountains provide important water sources for Xinjiang due to the abundance of snowfall, glaciers and rainfall. Complex topographic conditions and moisture sources lead to great climatic variability in the southern and northern slopes of the Tianshan Mountains. Nowadays, few studies have been conducted to evaluate the spatiotemporal patterns of Ep and identify the main influencing factors on the Ep in the Tianshan Mountains. Taking the 
southern and northern slopes of the Tianshan Mountains as the study area, this study applied the BPANN method to reconstruct the evaporation data of E601 type evaporation pan using long time series of Ep measured by the $20-\mathrm{cm}$ pans. The objectives of this study are (1) to analyze the interdecadal variations of Ep, and (2) to differentiate the main climatic factors influencing different cycles of Ep and their influencing paths in the southern and northern slopes of the Tianshan Mountains.

\section{Materials and methods}

\subsection{Study area}

The Tianshan Mountains situated in the middle of Xinjiang in Northwest China with coordinates of $39^{\circ} 43^{\prime}-43^{\circ} 53^{\prime} \mathrm{N}$ and $75^{\circ} 15^{\prime}-93^{\circ} 03^{\prime} \mathrm{E}$ are taken as the study area (Fig. 1). The Mountains' range spans $1,700 \mathrm{~km}$ from east to west and $250 \mathrm{~km}$ from north to south in China. Tianshan mountainous area covers about $5.7 \times 10^{5} \mathrm{~km}^{2}$, which accounts for more than $34.5 \%$ of the total area of Xinjiang. The alpine mountains result in huge differences in climate, topography and land surface properties at the northern and southern slopes. Glaciers exist in the top of the mountains, both grasslands and forestlands in the middle zone of mountains and oases at the bottom of mountains. The deserts extend to the centers of both northern and southern basins. The moisture sources of the Tianshan mountainous area mainly come from the Atlantic airflow brought by westerly circulation and the airflow from the Arctic Ocean. The mean annual precipitation of rugged terrains across the Tianshan Mountains is over $500 \mathrm{~mm}$ (Wei and $\mathrm{Hu}, 2009$ ). The moisture sources from westerly circulation head to the northern slope and fall as precipitation, which favors the northern slope to receive more precipitation than the southern slope. The mean annual precipitation at the northern and southern slopes is 194.0 and $111.3 \mathrm{~mm}$, respectively. The southern slope being warmer than the northern slope, part of the reason is that the alpine mountains effectively block the cold air from the north to transfer to the southern slope. The annual mean temperature at the northern and southern slopes is $6.2^{\circ} \mathrm{C}$ and $9.5^{\circ} \mathrm{C}$, respectively, with there being a large difference in the variation of temperature impacted by elevation at the northern and southern slopes. The temperature at the southern slope decreases faster than that at the northern slope (Wei and $\mathrm{Hu}, 2009$ ). Compared with other regions in Xinjiang, the reference evapotranspiration in the Tianshan Mountains is as low as to 800 to $1,000 \mathrm{~mm} / \mathrm{a}$ (Zhang and $\mathrm{Pu}$, 2011). And in growing season the daily rate of Ep $\mathrm{E}_{601}$ is less than $7 \mathrm{~mm} / \mathrm{d}$.

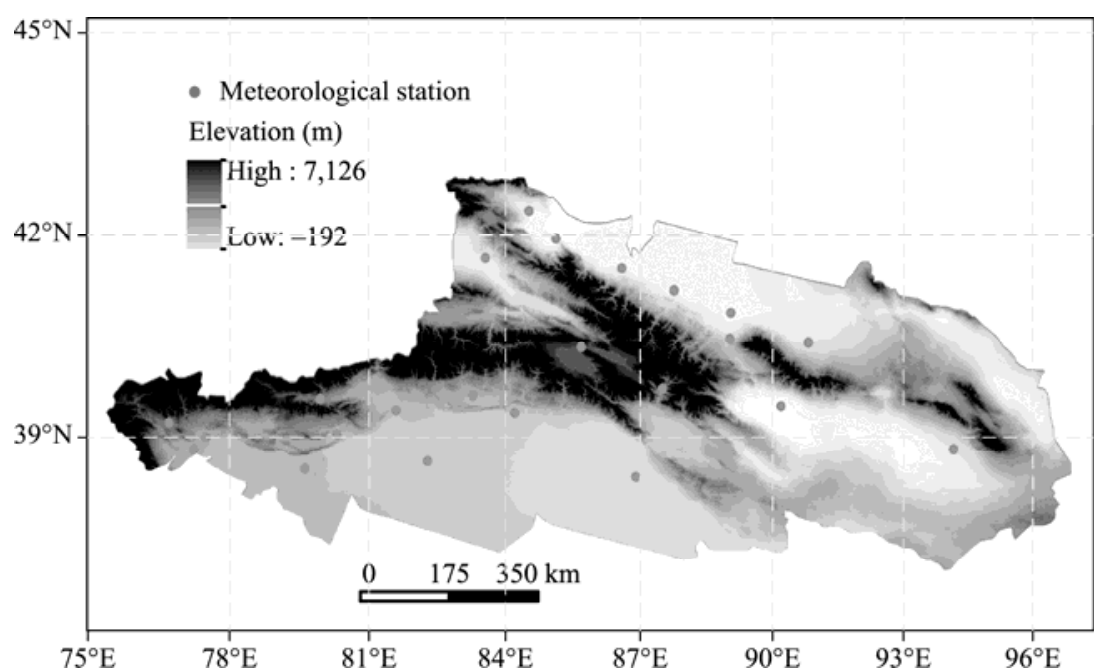

Fig. 1 The northern, southern slopes and the meteorological stations of the Tianshan Mountains

\subsection{Data processing}

The data used in this study include daily average temperature, wind speed, sunshine hours, actual water vapor pressure, and Ep measured by $20-\mathrm{cm}$ pan $\left(\mathrm{Ep}_{20}\right)$ and by the $\mathrm{Ep}_{\mathrm{E} 601}$ (Fig. 2). The 20-cm 
pan was installed at the height of $70 \mathrm{~cm}$ above the ground, and the measured value is always bigger than actual evaporation. Compared with $20-\mathrm{cm}$ pan, E601 type evaporation pan was installed in the ground with an area of $3,000 \mathrm{~cm}^{2}$. At a large scale, it could provide accurate information about evaporation and the measured value is close to actual evaporation. It is required to ensure the quality of the data, such as the credibility, homogeneity and missing data. The stations with missing datasets of selected climatic variables over $5 \%$ or missed more than $5 \mathrm{~d}$ in a month were removed. Otherwise, the missing data in a station was interpolated by its neighbor days and/or the reference of its neighbor stations. Based on the data availability of the selected climatic variables, the National Meteorological Information Centre of China can provide the data available only for 26 meteorological stations located at the southern and northern slopes from 1971 to 2012. Due to missing data as well as a relatively short historical data of EpE601, the time series of Ep E601 $_{6}$ for all used stations were interpolated for missing data and extrapolated back to 1971 by the method of BPANN using the $\mathrm{Ep}_{20}$ as data source, which made the time series of Ep $\mathrm{E}_{\mathrm{E} 61}$ comparable. The replenished $\mathrm{Ep}_{\mathrm{E} 601}$ and meteorological factors were decomposed by Ensemble Empirical Mode Decomposition (EEMD) to achieve their multiple time scales and determine the main meteorological factors which control the corresponding time scales of E $\mathrm{p}_{\mathrm{E} 601}$. Moreover, direct and indirect effects of different periods of $\mathrm{Ep}_{\mathrm{E} 601}$ at the northern and southern slopes were investigated by the method of path analysis.

\subsubsection{BPANN}

The E601 type evaporation pan has been recommended as a standard measuring instrument for water-surface evaporation capacity by World Meteorological Organization (WMO). However, the installation of the E601 type evaporation pan started in 1980s in Northwest China, so there are relatively short historical data of $\mathrm{Ep}_{\mathrm{E} 601}$. An extrapolation of reference evapotranspiration was implemented by BPANN (Jain et al., 2008; Dai et al., 2009) with climate factors.

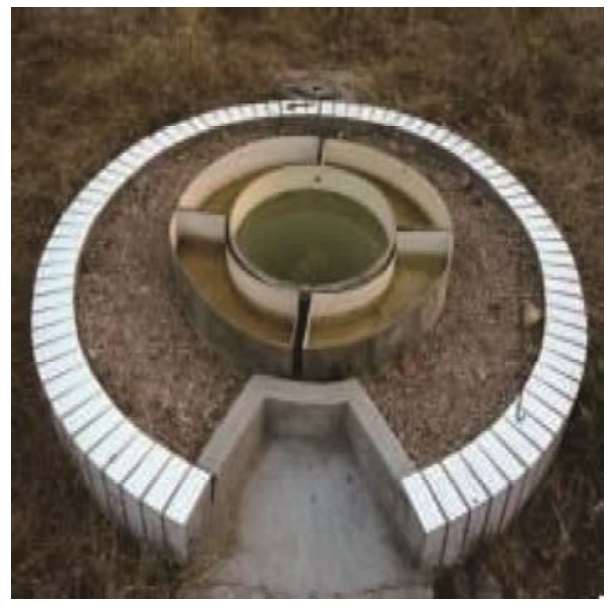

Fig. 2 The picture of the E601 type evaporation pan

In this study, a feed-forward network with the tan-sigmoid transfer function in the hidden layer and linear transfer function in the output layer was trained by BPANN which is useful for function approximation (or regression) problems and has a strong ability of nonlinear mapping. The Levenberg-Marquarde algorithm was used for training the network. The performance evaluation function was set as the mean square error (MSE) and regression $R^{2}$ value, and the default training times were 1,000. As the input and output vectors were the data of $\mathrm{Ep}_{20}$ and $\mathrm{Ep}_{\mathrm{E} 601}$, respectively, the neuron of input and output layer was 1 . The neuron of hidden layer is influenced by many factors including the neuron of input and output layers and the regularity contained in the training and validation samples. Then, the neuron of the hidden layer was set by the empirical formula as follow:

$$
n=\sqrt{m 1+m 2}+a
$$


Where $n$ represents the number of neuron of the hidden layer; $m 1$ and $m 2$ are the number of neuron of input and output layer, respectively; and $a$ is a constant from 1 to 10 .

\subsubsection{EEMD}

Based on the Empirical Mode Decomposition (EMD), we decomposed the replenished Ep E601 with added white noise into several intrinsic mode functions (IMF) by the method of EEMD (Wu and Huang, 2009) by means of Matlab 7.10. Not only did the EEMD preserve the original Ep information, but also overcame the problem of mode confusion. Specific steps in the EEMD are as follows: (1) Add a low intensity white noise to the original signal. The value of the white noise is 0.01-0.10 times of original signal's standard deviation; (2) Decompose the original signal with added white noise into IMFs; (3) Repeat the step of (1) and (2) for $n$ times, with various white noise series each time; and (4) For eliminating the influence of man-made white noise, we sum up the corresponding decomposed IMF of $n$ times, then average the summation for $n$ times. At the end, an ensemble set of IMFs can be obtained.

$$
C_{j}=\frac{1}{n} \sum_{i=1}^{n} C_{j, i}
$$

Where $C_{j}$ represents the $j^{\text {th }}$ decomposed IMF by EEMD, $j=1,2, \ldots, n$. In this study, the white noise added to the replenished Ep $\mathrm{E}_{\mathrm{E} 601}$ was 0.01 times of standard deviation of Ep, and the number of repetition times was 100 .

\subsubsection{Path analysis}

Path analysis extends the regression method for better understanding the causal structure of data (Kozak and Kang, 2006). The causal relationships between dependent and independent variables are described by a path chart in which the direct and indirect impacts of independent variables on the dependent variables can be clearly identified. The term "path coefficient" is defined as a "standardized version of linear regression weights that can be used to examine the possible causal linkage among statistical variables in the structural equation modeling approach." (Cai et al., 2008; Zheng et al., 2009). The correlation coefficient in the path analysis method is decomposed into direct and indirect path coefficients, i.e.:

$$
R_{i y}=P_{i y}+\sum_{i \neq j} R_{i j} P_{j y} .
$$

Where $R_{i y}$ is the correlation coefficient between independent variable $x_{i}$ and dependent variable $y$; $R_{i j}$ is the correlation coefficients between independent variable $x_{i}$ and $x_{j} ; P_{i y}$ is the direct path coefficient ( $x_{i}$ to $y$ ) which is the standard coefficient of linear regression equation; $P_{j y}$ is also the direct path coefficient $\left(x_{j}\right.$ to $y$ ); and $\sum_{i \neq j} R_{i j} P_{j y}$ is the sum of all the indirect path coefficients. A detailed description on estimation of path coefficient can be referred to Li et al. (2011) and Zhang et al. (2014).

\section{Results}

\subsection{The performance of BPANN}

From 1980s to 2001, nine stations were chosen for observing the Ep with both E601 type evaporation pan and 20-cm pan (Table 1), and seventeen stations were for 1990 to 2001. The Ep was observed by the E601 type evaporation pan in growing season and by the $20-\mathrm{cm}$ pan in non-growing season from 2001 to 2012. The BPANN was trained to extrapolate the Ep E601 $_{\text {back to }}$ 1971 and verified by using the observed $\mathrm{Ep}_{20}$ as input and $\mathrm{Ep}_{\mathrm{E} 601}$ as output. Topological structure, periods of training and verification and the performance of the model were shown in Table 1, which showed that the values of regression $R^{2}$ value and MSE were from 0.77 to 0.92 and 0.42 to 2.21 during the training period and from 0.62 to 0.97 and 0.11 to 1.80 during verification period, respectively. The results showed that the BPANN can perform a good regeneration of the Ep $\mathrm{E}_{601}$

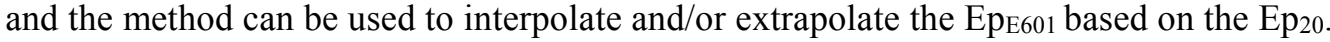


Table1 Statistics of the back-propagation artificial neural network (BPANN) training and verification performance at the 26 meteorological stations

\begin{tabular}{|c|c|c|c|c|c|c|c|}
\hline \multirow[t]{2}{*}{ Station } & \multirow{2}{*}{$\begin{array}{l}\text { Topological } \\
\text { structure }\end{array}$} & \multirow{2}{*}{$\begin{array}{l}\text { Period of } \\
\text { training data }\end{array}$} & \multirow{2}{*}{$\begin{array}{l}\text { Period of } \\
\text { verification data }\end{array}$} & \multicolumn{2}{|c|}{$\begin{array}{c}\text { Training } \\
\text { performance indices }\end{array}$} & \multicolumn{2}{|c|}{$\begin{array}{c}\text { Verification performance } \\
\text { indices }\end{array}$} \\
\hline & & & & $R^{2}$ & MSE (mm) & $R^{2}$ & MSE (mm) \\
\hline Yining & $(1,9,1)$ & $1993-2001$ & 1984-1992 & 0.78 & 0.65 & 0.88 & 0.11 \\
\hline Bole & $(1,7,1)$ & 1993-2001 & 1985-1992 & 0.84 & 0.77 & 0.84 & 0.68 \\
\hline Wenquan & $(1,7,1)$ & $2000-2001$ & 1998-1999 & 0.86 & 0.56 & 0.81 & 0.39 \\
\hline Caijiahu & $(1,12,1)$ & $2000-2001$ & 1998-1999 & 0.84 & 1.40 & 0.86 & 0.78 \\
\hline Jinghe & $(1,6,1)$ & 2000-2001 & 1998-1999 & 0.84 & 0.82 & 0.84 & 0.46 \\
\hline Qitai & $(1,11,1)$ & 1995-2001 & 1987-1994 & 0.83 & 0.94 & 0.87 & 0.45 \\
\hline Shihezi & $(1,9,1)$ & 2000-2001 & 1998-1999 & 0.81 & 0.91 & 0.79 & 0.61 \\
\hline Urumqi & $(1,8,1)$ & $1993-2001$ & 1984-1992 & 0.88 & 1.03 & 0.96 & 0.12 \\
\hline Wusu & $(1,7,1)$ & 2000-2001 & 1998-1999 & 0.81 & 1.63 & 0.78 & 1.36 \\
\hline Yiwu & $(1,6,1)$ & $2000-2001$ & 1998-1999 & 0.84 & 0.79 & 0.89 & 0.43 \\
\hline Barkol & $(1,10,1)$ & $2000-2001$ & 1998-1999 & 0.77 & 1.40 & 0.68 & 1.40 \\
\hline Wuqia & $(1,7,1)$ & $2000-2001$ & 1998-1999 & 0.90 & 1.09 & 0.84 & 1.80 \\
\hline Kashi & $(1,16,1)$ & 1997-2001 & 1991-1996 & 0.83 & 0.99 & 0.88 & 0.61 \\
\hline Artux & $(1,16,1)$ & $1993-2001$ & 1985-1992 & 0.86 & 2.21 & 0.94 & 0.31 \\
\hline Aksu & $(1,20,1)$ & $1993-2001$ & 1984-1992 & 0.84 & 0.79 & 0.88 & 0.35 \\
\hline Aral & $(1,8,1)$ & $2000-2001$ & 1998-1999 & 0.79 & 0.95 & 0.72 & 0.71 \\
\hline Akqi & $(1,8,1)$ & 2000-2001 & 1998-1999 & 0.78 & 1.08 & 0.62 & 0.99 \\
\hline Kalpin & $(1.13,1)$ & $2000-2001$ & 1998-1999 & 0.84 & 1.21 & 0.86 & 0.65 \\
\hline Baicheng & $(1,8,1)$ & $2000-2001$ & 1998-1999 & 0.88 & 0.43 & 0.90 & 0.29 \\
\hline Bachu & $(1,10,1)$ & $2000-2001$ & 1998-1999 & 0.83 & 0.82 & 0.82 & 0.58 \\
\hline Bakguntay & $(1,7,1)$ & 2000-2001 & 1998-1999 & 0.91 & 0.42 & 0.89 & 0.37 \\
\hline Bayanbulak & $(1,13,1)$ & 2000-2001 & 1998-1999 & 0.77 & 0.68 & 0.77 & 0.61 \\
\hline Korla & $(1,6,1)$ & 1993-2001 & 1984-1992 & 0.92 & 0.76 & 0.97 & 0.11 \\
\hline Kuqa & $(1,18,1)$ & $2000-2001$ & 1998-1999 & 0.92 & 0.81 & 0.89 & 0.50 \\
\hline Hami & $(1,15,1)$ & 1995-2001 & 1987-1994 & 0.85 & 0.93 & 0.86 & 0.37 \\
\hline Turpan & $(1,7,1)$ & $1993-2001$ & 1985-1992 & 0.84 & 1.09 & 0.93 & 0.34 \\
\hline
\end{tabular}

Note: In topological structure $(\mathrm{x}, \mathrm{y}, \mathrm{z}), \mathrm{x}$ is the number of neuron of input, $\mathrm{y}$ is the number of neuron of the hidden layer, and $\mathrm{z}$ is the number of neuron of output. MSE, mean square error.

\subsection{Time series EpE601 in both slopes}

Average Eps according to the data of the Ep $\mathrm{E}_{601}$ at 26 meteorological stations at the northern and southern slopes of the Tianshan Mountains from 1971 to 2012 were shown in Fig. 3. The mean Ep with $902.9 \mathrm{~mm}$ in the southern slope was greater than that with $816.1 \mathrm{~mm}$ in the northern slope. Ep experienced a significant decreasing trend $(P<0.05)$ with a rate of $27.4 \mathrm{~mm} / 10$ a at the southern slope from 1971 to 2012. Ep in the northern slope slightly decreased with a minor rate of 8.9 $\mathrm{mm} / 10 \mathrm{a}(P<0.01)$. Figure 3 indicated that Eps in the northern and southern slopes had obvious interdecadal variations. The variations can be identified as 3 phases and periodic variations can be observed with scales of 3-4 and 7-8 years. Eps in both slopes did not sharply decrease until early $1980 \mathrm{~s}$, but they increased since late 1990s. The decrease in Eps in the northern and southern slopes from early 1980 s to late 1990 s was about 228.6 and $255.6 \mathrm{~mm}$, respectively. 

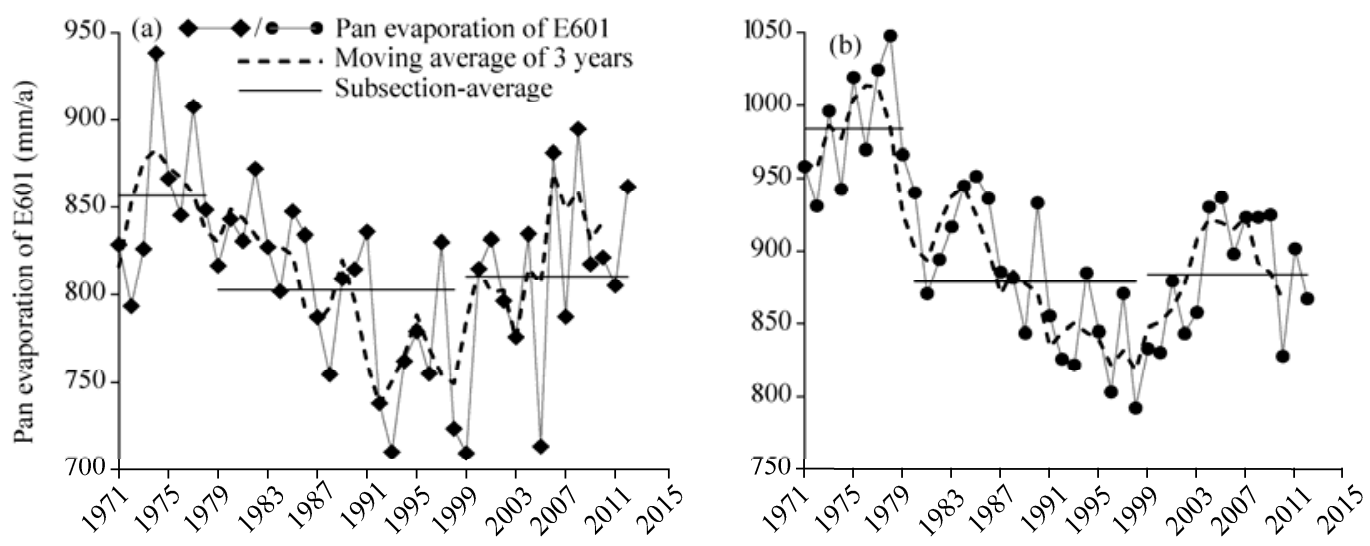

Fig. 3 Interdecadal variations of EpE601 from 1971 to 2012 in the northern (a) and southern (b) slopes of the Tianshan Mountains

\subsection{Interdecadal variation of EpE601 modelling by EEMD}

Ep $\mathrm{E}_{\mathrm{E} 61}$ at the northern and southern slopes was decomposed by EEMD. Four intrinsic mode functions $\left(\mathrm{IMF}_{\mathrm{S}}\right)$ were selected, which implied that Ep $\mathrm{p}_{\mathrm{E} 601}$ at the northern and southern slopes across the Tianshan Mountains contained multiple time scales (Fig. 4). Among the four IMFs, the IMF1 at both slopes fluctuated widely and showed a periodic variation within 3-4 years. The IMF1 did not show a notable fluctuation at the northern slope during 1980s (Fig. 4a). Meanwhile, the amplitude of IMF1 enlarged at the northern slope since 2000. The IMF2 at both slopes periodically changed with cycles of 7-8 years. The amplitude of IMF2 at both slopes changed with different directions, i.e. the amplitude of IMF2 was getting larger at the northern slope and smaller at the southern slope (Figs. 4c and d). The amplitude of IMFs at both slopes decreased with the increase of the order. IMF3 at both slopes presented little variation from 1970s to late 1990s, but both had a large fluctuation after 1990s (Figs. 4e and f). The period of the IMF4 at both slopes may belong to the components of longer cycle with little change (Figs. $4 \mathrm{~g}$ and $\mathrm{h}$ ).

There are various climatic factors influencing $\mathrm{Ep}_{\mathrm{E} 601}$. For determining the main meteorological factors in controlling various cycles of E $\mathrm{p}_{\mathrm{E} 601}$ at the northern and southern slopes, we decomposed the series data of climatic factors including wind speed, actual water vapor pressure, average temperature and sunshine duration using the EEMD. Considering incomparability caused by different dimensions of climatic factors and $\mathrm{Ep}_{\mathrm{E} 601}$, the decomposed IMFs of the climatic factors and $\mathrm{Ep}_{\mathrm{E} 601}$ were standardized. At the northern slope, the decomposed IMF1 of Ep $\mathrm{E} 601$ varied similarly to the decomposed IMF1 of average temperature and evolved oppositely to the decomposed IMF1 of actual water vapor pressure (Figs. 5a and b). At the southern slope, the

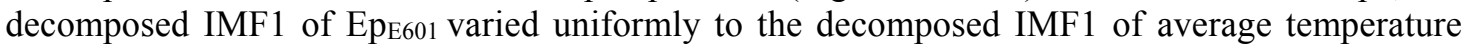
and sunshine duration. The decomposed IMF1 of E $\mathrm{p}_{\mathrm{E} 601}$ performed same periodic variations and similar wave's crests and troughs with the decomposed IMF1 of average temperature and sunshine duration, respectively (Figs. $5 \mathrm{c}$ and d). The results indicated that the cycle of Ep $\mathrm{p}_{\mathrm{E} 601}$ within 3-4 years at the northern and southern slopes was mainly controlled by average temperature and actual water vapor pressure, average temperature and sunshine duration, respectively. The variations of the decomposed IMF2 of Ep $\mathrm{E}_{\mathrm{E} 01}$ and actual water vapor pressure had a negative relationship, and the decomposed IMF2 of Ep 6601 positively related with wind speed with same cycles of 7-8 years at the northern slope (Figs. 5e and f). The negative correlation between the $\mathrm{Ep}_{\mathrm{E} 601}$ and actual water vapor pressure was further verified by the results from path analysis. At the southern slope, the variation of the decomposed IMF2 of E $\mathrm{p}_{\mathrm{E} 601}$ and average temperature was similar (Fig. 5g). The decomposed IMF2 of Ep duration identically varied with the cycles of 7-8 years at the southern slope (Fig. $5 \mathrm{~h}$ ). The results revealed that the variation of $E \mathrm{p}_{\mathrm{E} 601}$ with cycles of 7-8 years was mainly dominated by actual water vapor pressure and wind speed at the northern slope, but it was largely controlled by average temperature and sunshine duration at the southern slope. 


\subsection{Direct and indirect effects of meteorological factors on Ep}

According to the path analysis, the direct and indirect effects of the meteorological factors on Ep 6601 were shown in Table 2. The 3-4 years cycle of Ep 6601 was very significantly correlated with that of average temperature and actual water vapor pressure at the northern slope. The direct path coefficient of average temperature on 3-4 years cycle at the northern slope was 0.258 , while the actual water vapor pressure imposed a direct negative effect on 3-4 years cycle of Ep a path coefficient of -0.515 . The indirect effects of average temperature and actual water vapor pressure on 3-4 years cycle of EpE601 at the northern slope were relatively small. Although
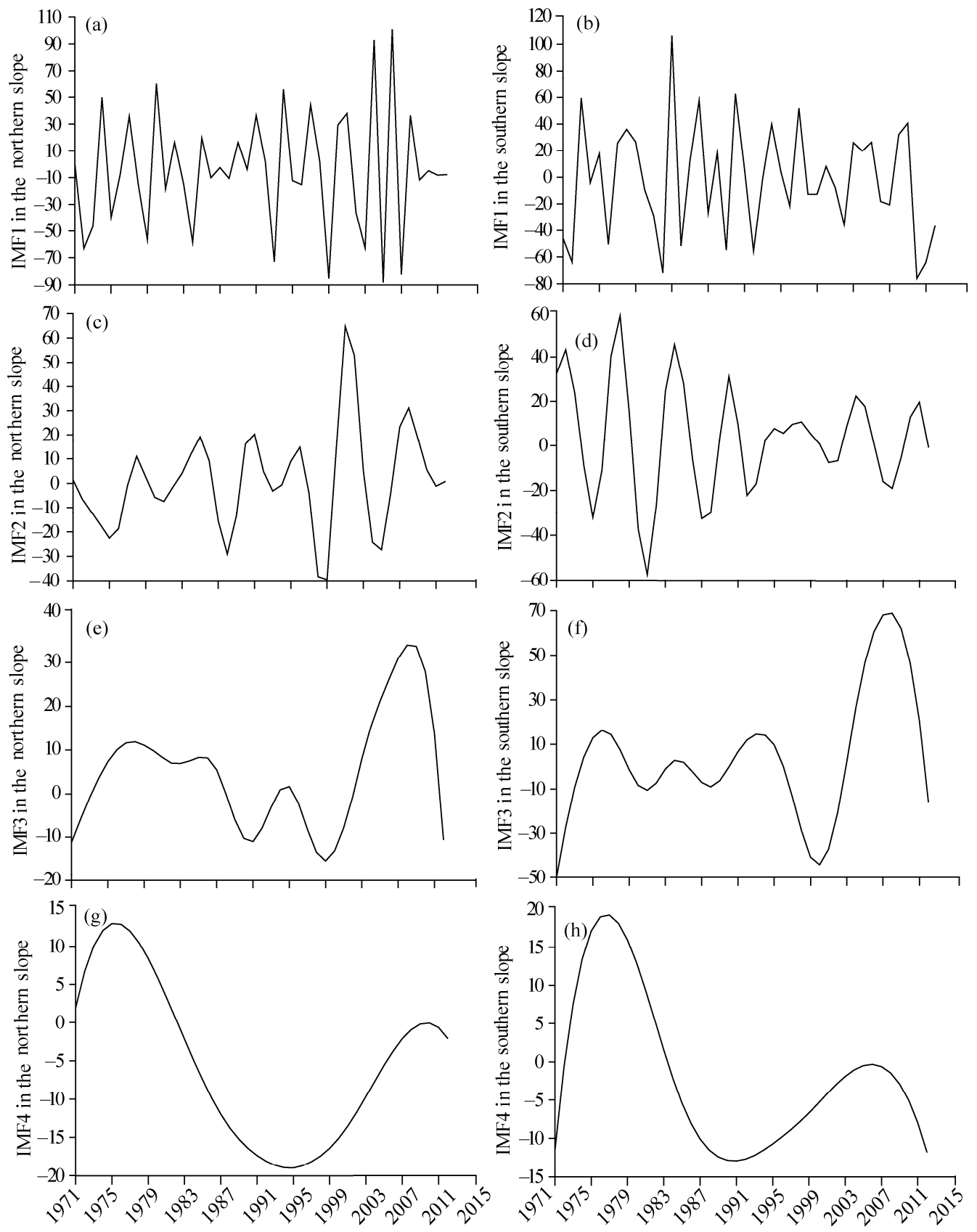

Fig. 4 Interdecadal variations of Epe601 from 1971 to 2012 in the northern (a, c, e and g) and southern (b, d, f and $\mathrm{g}$ ) slopes of the Tianshan Mountains modelling by the Ensemble Empirical Mode Decomposition 

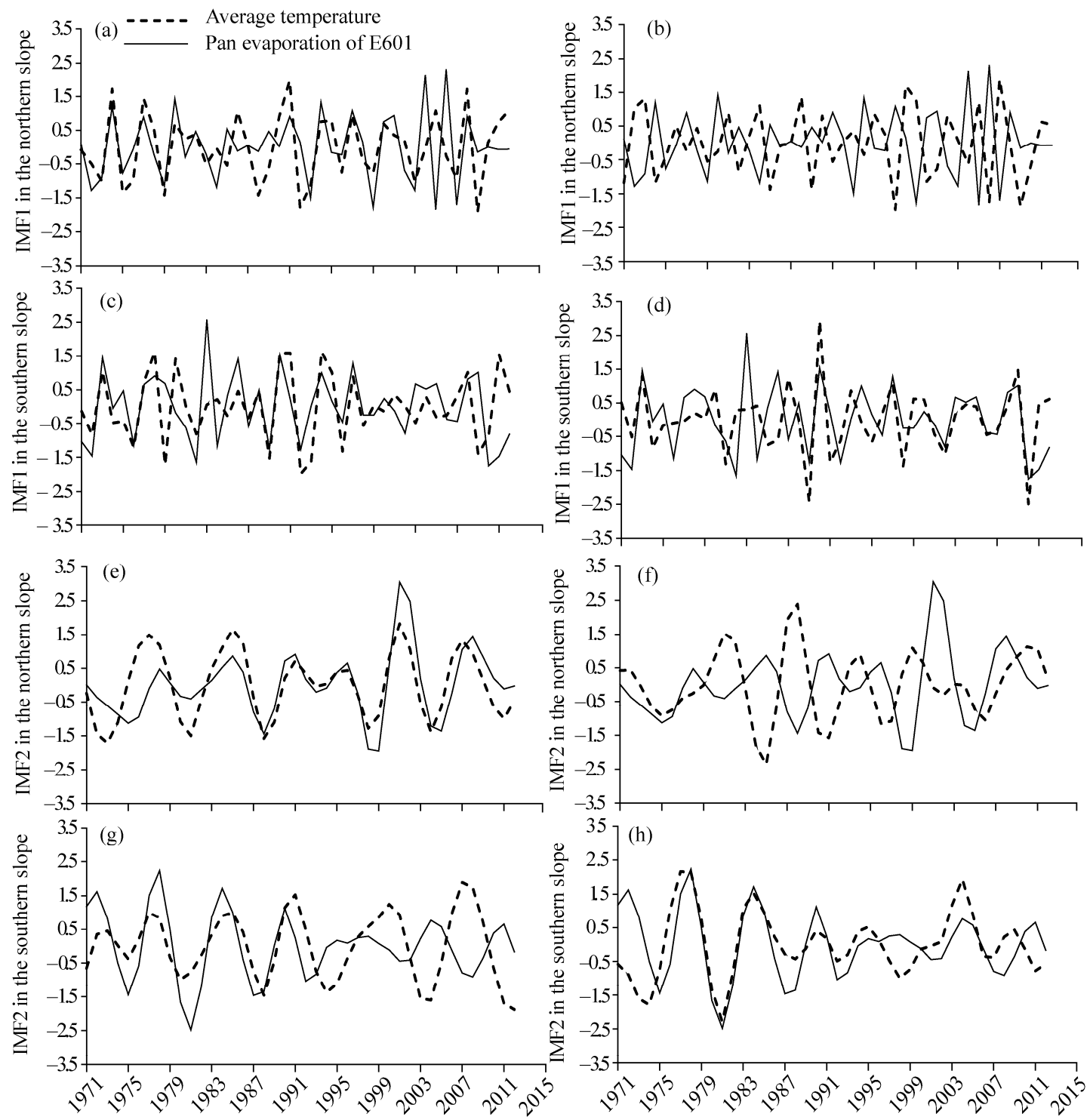

Fig. 5 The comparison between decomposed results of EpE601 and average temperature

3-4 years cycle of E $\mathrm{p}_{\mathrm{E} 601}$ significantly correlated with that of wind speed in the northern slope, its direct effect was small. Wind speed indirectly impacted 3-4 years cycle of Ep E601 through actual water vapor pressure with a path coefficient of 0.274 . Sunshine duration also showed a significant correlation with the 3-4 years cycle of $\mathrm{Ep}_{\mathrm{E} 601}$ at the northern slope, but sunshine duration did not directly influence 3-4 years cycle of Ep $\mathrm{E}_{\mathrm{E} 61}$. However, the indirect path coefficient between sunshine duration and $\mathrm{Ep}_{\mathrm{E} 601}$ through average temperature reached up to 0.124, which indicated that the influence of sunshine duration on $\mathrm{Ep}_{\mathrm{E} 601}$ was realized through average temperature at the northern slope. The exception was found at 7-8 years cycle of E $p_{\mathrm{E} 601}$, which only significantly correlated with that of wind speed in the northern slope with the direct effect on E $p_{E 601}$.

The 3-4 years cycle of Ep $\mathrm{E} 601_{1}$ had significant correlations with that of average temperature and sunshine duration at the southern slope. Sunshine duration at the southern slope directly influenced Ep $\mathrm{E}_{601}$ with a direct path coefficient of 0.370 , while average temperature equally affected $\mathrm{Ep}_{\mathrm{E} 601}$ through direct and indirect paths. The average temperature directly influenced Ep $p_{E 601}$ with a direct path coefficient of 0.281 , but indirectly through sunshine duration with an 
Table 2 Direct and indirect effects of meteorological factors on the pan-evaporations at 3-4 years (IMF1) and 7-8 years cycles (IMF2) at the northern and southern slopes of the Tianshan Mountains

\begin{tabular}{|c|c|c|c|c|c|c|c|}
\hline \multirow{3}{*}{ Item } & & \multirow{3}{*}{$\begin{array}{l}\text { Correlation } \\
\text { coefficient }\end{array}$} & \multicolumn{5}{|c|}{ Path coefficient } \\
\hline & & & \multirow{2}{*}{$\begin{array}{l}\text { Direct } \\
\text { effect }\end{array}$} & \multicolumn{4}{|c|}{ Indirect effects } \\
\hline & & & & $\begin{array}{l}\text { Wind } \\
\text { speed }\end{array}$ & $\begin{array}{c}\text { Average } \\
\text { temperature }\end{array}$ & $\begin{array}{c}\text { Actual water } \\
\text { vapor pressure }\end{array}$ & $\begin{array}{r}\text { Sunshine } \\
\text { duration } \\
\end{array}$ \\
\hline \multicolumn{8}{|l|}{ Northern slope } \\
\hline Wind speed & IMF1 & $0.429^{* *}$ & 0.123 & & 0.023 & 0.269 & 0.014 \\
\hline Average temperature & IMF1 & $0.428^{* *}$ & 0.258 & $0.011-0.064$ & & 0.056 & 0.103 \\
\hline Actual water vapor pressure & IMF1 & $-0.636^{* *}$ & -0.515 & 0.008 & -0.028 & & -0.029 \\
\hline Sunshine duration & IMF1 & $0.415^{* *}$ & 0.214 & & 0.124 & 0.070 & \\
\hline Wind speed & IMF2 & $0.686^{* *}$ & 0.774 & & -0.002 & -0.075 & -0.012 \\
\hline Average temperature & IMF2 & -0.024 & -0.039 & 0.033 & & -0.014 & -0.003 \\
\hline Actual water vapor pressure & IMF2 & -0.282 & 0.138 & -0.421 & 0.004 & & -0.003 \\
\hline Sunshine duration & IMF2 & 0.023 & 0.109 & -0.084 & 0.001 & -0.004 & \\
\hline \multicolumn{8}{|l|}{ Southern slope } \\
\hline Wind speed & IMF1 & 0.220 & 0.154 & & 0.001 & -0.046 & 0.111 \\
\hline Average temperature & IMF1 & $0.377^{*}$ & 0.281 & 0.001 & & -0.008 & 0.103 \\
\hline Actual water vapor pressure & IMF1 & -0.054 & 0.162 & -0.044 & -0.014 & & -0.158 \\
\hline Sunshine duration & IMF1 & $0.425^{* *}$ & 0.370 & 0.046 & 0.078 & -0.069 & \\
\hline Wind speed & IMF2 & 0.086 & 0.459 & & -0.569 & 0.186 & 0.011 \\
\hline Average temperature & IMF2 & 0.210 & 0.813 & -0.321 & & -0.358 & 0.076 \\
\hline Actual water vapor pressure & IMF2 & 0.107 & 0.588 & 0.145 & -0.495 & & -0.131 \\
\hline Sunshine duration & IMF2 & $0.569^{* *}$ & 0.588 & 0.009 & 0.105 & -0.131 & \\
\hline
\end{tabular}

Note: ${ }^{*}$ and ${ }^{* *}$ indicate significance at $P<0.05$ and $P<0.01$ levels, respectively.

indirect path coefficient of 0.103 . The direct effect of wind speed with a direct path coefficient of 0.154 was closely equal to the indirect effect of wind speed through sunshine duration with an indirect path coefficient of 0.111 at 3-4 years cycle of Ep $p_{\mathrm{E} 601}$. The impact of actual water vapor pressure on Ep $\mathrm{p}_{\mathrm{E} 61}$ was indirect through sunshine duration path with a negative indirect path coefficient of -0.158 . The 7-8 years cycle of Ep $\mathrm{E}_{\mathrm{E} 01}$ significantly correlated with that of sunshine duration at the southern slope. Sunshine duration positively influenced Ep E601 through a direct path with a path coefficient of 0.588. Average temperature, wind speed and actual water vapor pressure were not remarkable relevance with the 7-8 years cycle of Ep $\mathrm{E}_{\mathrm{E} 601}$. The direct effect of wind speed with a direct path coefficient of 0.459 was almost equivalent to the sum of indirect effects of wind speed through average temperature with an indirect path coefficient of -0.569 , actual water vapor pressure with an indirect path coefficient of 0.186 and sunshine duration with an indirect path coefficient of 0.111 . Results in this study indicated that the most significant meteorological factor influencing Ep is actual water vapor pressure at the northern slope, while it is sunshine duration at the southern slope.

\section{Discussion}

Evaporation is controlled by various meteorological factors, such as wind speed, relative humidity, sunshine duration, air temperature and so on (Xu et al., 2006; Wang and Liang, 2008; Sharifi and Dinpashoh, 2014). As an interactive product of various meteorological factors, evaporation was highly sensitive to changes in annual precipitation (Villarreal et al., 2016) as well as temperature 
and vapor pressure (Goyal, 2004; Li et al., 2015). The changes of temperature and precipitation under the context of climate change led to the fluctuation of evaporation (Ren et al., 2005; Qin et al., 2007). As a key process of hydrological cycle and phase transformation of water, evaporation is of important significance in determining ecosystem productivity and maintaining the stability of environment. Evaporation and precipitation resulting in the distribution of water are two tremendous courses to influence runoff (Wang et al., 2011; Zhang et al., 2011). Compared with the positive driving force of precipitation to runoff, the driving force of potential evaporation to runoff was negative (Zhang et al., 2011). Therefore, the change in evaporation can be used as an alternative parameter to reflect climate change and the decadal change of evaporation implies the information on the change of local ecosystem and hydrological processes under climate change (Brutsaert and Parlange, 1998; Su et al., 2015).

Decreasing Ep has been observed in most parts of the world, including Australia (Roderick and Farquhar, 2004), New Zealand (Roderick and Farquhar, 2005), dry and humid regions of the United States (Lawrimore and Peterson, 2000), India (Chattopadhyay and Hulme, 1997), China (Thomas, 2000; Liu et al., 2004; Chen et al., 2005; Liu et al., 2009; Yang and Yang, 2012; Li et al., 2013; Zhang et al., 2015) and South Africa (Hoffman et al., 2001). Debates on the causes still remained. The persuasive argument is that the weakening ability of solar radiation results in the decreasing amount of Ep (Peterson, 1995; Michael and Graham, 2002; Roderick and Farquhar, 2002). Eps at the northern and southern slopes across the Tianshan Mountains also showed decreasing trends which are consistent with most parts of the world. However, there are some regions where the trends of Ep are increasing. Wang et al. (2011) reported an increasing trend of $\mathrm{Ep}_{20}$ in Maqu county of Gansu province in China. Shen and Sheng (2008) found that $\mathrm{Ep}_{20}$ in the Greater Khingan and Beishan mountains increased from 1957 to 2001. In the present study, Eps at both the northern and southern slopes showed significant interdecadal variations within cycles of 3-4 and 7-8 years. Eps at both the slopes sharply decreased from early 1980s, but increased after late 1990s. Based on the data from 126 ground-based meteorological observation stations in the arid region of China, Shen et al. (2010) reported the phenomenon of an increase trend in $\mathrm{Ep}_{20}$ in 1990s.

By combining the method of EEMD and path analysis, this study explored the main climatic factors in controlling various cycles of $\mathrm{Ep}_{\mathrm{E} 601}$. Wind speed made the decrease of Ep, especially in the Northwest China (Shen et al., 2010; Wang et al., 2012) and the Tibetan Plateau (Zhang et al., 2007). Su et al. (2015) highlighted that the interdecadal variation of evaporation on the basis of reanalysis data was driven by the change of temperature, while the inter-annual variation was constrained by the water supply conditions. However, the results at the northern and southern slopes of the Tianshan Mountains were different. This study showed that the variation of Ep E601 with cycles of 3-4 years was mainly related to average temperature and actual water vapor pressure at the northern slope, and average temperature and sunshine duration at the southern slope. The different causes of the variation of Ep $\mathrm{E} 601$ with cycles of 3-4 years at both the slopes might be explained by the fact that the northern slope could receive more precipitation because air moisture mainly comes from westerly circulation and falls as precipitation when it heads to the northern slope, while the southern slope has more sunshine. Actual water vapor pressure as the major influencing factor of Ep agreed with the result of $\mathrm{Xu}$ et al. (2006). For the variation of Ep $\mathrm{E} 601_{1}$ with 7-8 years cycles, the main influential factors were wind speed and actual water vapor pressure at the northern slope, and average temperature and sunshine duration at the southern slope. Both wind speed and actual water vapor pressure acted through different ways to influence the $\mathrm{Ep}_{\mathrm{E} 601}$ in both slopes because the interactions existed among meteorological factors. However, the interdecadal variations of $\mathrm{Ep}_{\mathrm{E} 601}$ in both slopes cannot be fully explained by the direct effect of a single factor. Due to the existence of the interactions among meteorological factors, one meteorological factor might influence Ep E601 through another one with an indirect path. One meteorological factor with a little direct effect on the EpE601 may interact with another factor, which significantly influences it through an indirect path. At the northern slope, the effect of wind speed on the variation of Ep $\mathrm{E}_{601}$ with the cycle of 3-4 years was realized by the indirect path through actual water vapor pressure. Actual water vapor pressure played an important role by 
indirectly influencing on the variation of Ep $\mathrm{E}_{601}$ with the cycle of 7-8 years through wind speed. The interaction between wind speed and actual water vapor pressure should be appreciated at the northern slope. At the southern slope, wind speed had both direct and indirect effects on the periodic variation of $\mathrm{Ep}_{\mathrm{E} 601}$, but there were different paths. Its indirect effect on the cycle of 3-4 years was realized through sunshine duration, while wind speed indirectly influenced the cycle of 7-8 years through average temperature. Except for its direct effect, actual water vapor pressure indirectly influenced the variation of $\mathrm{Ep}_{\mathrm{E} 601}$ with the cycle of 3-4 years through sunshine duration and with the cycle of 7-8 years through average temperature. The results demonstrated that average temperature and sunshine duration not only directly influenced the variation of Ep $\mathrm{p}_{\mathrm{E} 601}$, but also indirectly affected the variation of $\mathrm{Ep}_{\mathrm{E} 601}$ through by interacting with other factors at the southern slope.

The time series of $\mathrm{Ep}_{\mathrm{E} 601}$ data were so short that the value in use of $\mathrm{Ep}_{\mathrm{E} 601}$ data is petit. Ep $\mathrm{p}_{\mathrm{E} 601}$ was replenished on the basis of the Ep 20 by using the ratio method to extend the Ep $\mathrm{p}_{\mathrm{E} 601}$ time series (Jia et al., 2009; Jin 2009; Aydaraili and Huang, 2011; Wei and Liu, 2011). In this study, EpE601 was replenished from 1971 to 2012 using the method of BPANN. The BPANN with a satisfactory capability to interpolate and/or extrapolate the $\mathrm{Ep}_{\mathrm{E} 601}$ using $\mathrm{Ep}_{20}$ as input helps providing longer historical data to support the assessment of hydrological process and climate change in the Tianshan Mountains.

\section{Conclusions}

A change in Ep is likely to have a considerable effect on local hydrological cycle which guarantees the quantity of water resources to some extent. Ep at the southern slope decreased faster than that at the northern slope. Obvious interdecadal variations of Ep at both slopes existed with cycles of 3-4 and 7-8 years under the different controlling meteorological factors. Sunshine duration and average temperature directly affected the variation of E $\mathrm{p}_{\mathrm{E} 601}$ at the southern slope with cycles of 3-4 and 7-8 years, while the variation of $E p_{\mathrm{E} 601}$ at the northern slope with the cycle of 3-4 years was controlled by average temperature and actual water vapor pressure, and the variation of Ep $\mathrm{E}_{\mathrm{E} 01}$ with the cycle of 7-8 years was driven by wind speed and actual water vapor pressure. Interactive influences among climatic factors through different indirect paths played an important role in the periodic variation of Ep. The present study provided a preliminary reference for climate change assessment and water resource planning in arid regions. Since most meteorological stations are located at the mid and low altitude zones in study area, the lack of observations at the high altitude zone may cause overestimates or underestimates of the Ep. Due to the topographic heterogeneity and complexity in the Tianshan Mountains, the assessment based on station observations may not fully represent the pattern of regional climate change. It is suggested to integrate the data from both observation and Weather Research and Forecasting Model for characterizing the regional variation pattern of Ep in further study.

\section{Acknowledgements}

This work was funded by the National Basic Research Program of China (2012CB956204) and the Special Funds for Key Laboratories of the Xinjiang Uygur Autonomous Region (2014KL015).

\section{References}

Aydaraili X, Huang M. 2011. Comparative analysis of observed data between E-601 evaporator and $20 \mathrm{~cm}$ pan in Tianshan River Basin. Journal of China Hydrology, 31(4): 76-80. (in Chinese)

Brutsaert W, Parlange M B. 1998. Hydrologic cycle explains the evaporation paradox. Nature, 396(6706): 30.

Cai J B, Liu Y, Xu D, et al. 2008. Sensitivity analysis on water deficit indicator of winter wheat based on path analysis theory. Journal of Hydraulic Engineering, 39(1): 83-89. (in Chinese)

Chattopadhyay N, Hulme M. 1997. Evaporation and potential evapotranspiration in India under conditions of recent and future climate change. Agricultural and Forest Meteorology, 87(1): 55-73.

Chen D L, Gao G, Xu C Y, et al. 2005. Comparison of the Thornthwaite method and pan data with the standard 
Penman-Monteith estimates of reference evapotranspiration in China. Climate Research, 28(2): 123-132.

Dai X Q, Shi H B, Li Y S, et al. 2009. Artificial neural network models for estimating regional reference evapotranspiration based on climate factors. Hydrological Processes, 23(3): 442-450.

Goyal R K. 2004. Sensitivity of evapotranspiration to global warming: a case study of arid zone of Rajasthan (India). Agricultural Water Management, 69(1): 1-11.

Hobbins M T, Ramírez J A, Brown T C. 2004. Trends in pan evaporation and actual evapotranspiration across the conterminous U.S.: paradoxical or complementary?. Geophysical Research Letters, 31(13): L13503.

Hoffman M T, Cramer M D, Gillson L, et al. 2001. Pan evaporation and wind run decline in the Cape Floristic Region of South Africa (1974-2005): implications for vegetation responses to climate change. Climatic Change, 109(3-4): 437-452.

Huang Q H. 2000. Contrast analysis of $\mathrm{E}_{601}$ versus small-sized evaporation gauge. Meteorological Monthly, 26(10): 45-48. (in Chinese)

Jain S K, Nayak P C, Sudheer K P. 2008. Models for estimating evapotranspiration using artificial neural networks, and their physical interpretation. Hydrological Processes, 22(13): 2225-2234.

Ji Y H, Zhou G S. 2011. Important factors governing the incompatible trends of annual pan evaporation: evidence from a small scale region. Climatic Change, 106(2): 303-314.

Jia L, Xi G, Liu S, et al. 2009. Regional estimation of daily to annual regional evapotranspiration with MODIS data in the Yellow River Delta wetland. Hydrology and Earth System Sciences, 13(10): 1775-1787.

Jin L. 2009. Research on the relationship of water evaporations between two different evaporators. Journal of Water Resources and Water Engineering, 20(2): 117-118. (in Chinese)

Kozak M, Kang M S. 2006. Note on modern path analysis in application to crop science. Communications in Biometry and Crop Science, 1(1): 32-34.

Lawrimore J H, Peterson T C. 2000. Pan evaporation trends in dry and humid regions of the United States. Journal of Hydrometeorology, 1(6): 543-546.

Li S S, Zhang F Y, Bai L, et al. 2015. Spatiotemporal variation and sensitivity of reference crop evapotranspiration during growth season in Northern Xinjiang. Chinese Journal of Agrometeorology, 36(6): 683-691. (in Chinese)

Li X M, Li L H, Guo L P, et al. 2011. Impact of climate factors on runoff in the Kaidu River watershed: path analysis of 50-year data. Journal of Arid Land, 3(2): 132-140.

Li Z, Chen Y N, Shen Y J, et al. 2013. Analysis of changing pan evaporation in the arid region of Northwest China. Water Resources Research, 49(4): 2205-2212.

Liu B H, Xu M, Henderson M, et al. 2004. A spatial analysis of pan evaporation trends in China, 1955-2000. Journal of Geophysical Research: Atmospheres (1984-2012), 109(D15): D15102.

Liu M, Shen Y J, Zeng Y, et al. 2009. Changing trend of pan evaporation and its cause over the past 50 years in China. Acta Geographica Sinica, 64(3): 259-269. (in Chinese)

Liu X N, Wang S Q, Wu Z X, et al. 1998. Comparative analysis on two kinds of observed evaporation data in China. Quarterly Journal of Applied Meteorology, 9(3): 321-328. (in Chinese)

Michael L R, Graham D F. 2002. The cause of decreased pan evaporation over the past 50 yeas. Science, 298(15): $1410-1411$.

Peterson T V. 1995. Evaporation losing its strength. Nature, 377: 687-688.

Qin D H, Chen Z L, Luo Y, et al. 2007. Updated understanding of climate change sciences. Adcances in Climate Change Research, 3(2): 63-73. (in Chinese)

Ren G Y, Guo J, Xu M Z, et al. 2005. Climate changes of China's mainland over the past half century. Acta Meteorologica Sinica, 63(6): 942-956. (in Chinese)

Roderick M L, Farquhar G D. 2002. The cause of decreased pan evaporation over the past 50 years. Science, 298(5597): $1410-1411$.

Roderick M L, Farquhar G D. 2004. Changes in Australian pan evaporation from 1970 to 2002. International Journal of Climatology, 24(9): 1077-1090.

Roderick M L, Farquhar G D. 2005. Changes in New Zealand pan evaporation since the 1970s. International Journal of Climatology, 25(15): 2031-2039.

Roderick M L, Hobbins M T, Farquhar G D. 2009. Pan evaporation trends and the terrestrial water balance. II. Energy balance and interpretation. Geography Compass, 3(2): 761-780.

Sharifi A, Dinpashoh Y. 2014. Sensitivity analysis of the Penman-Monteith reference crop evapotranspiration to climatic variables in Iran. Water Resources Management, 28(15): 5465-5476.

Shen S H, Sheng Q. 2008. Changes in pan evaporation and its cause in China in the last 45 years. Acta Meteorologica Sinica, 66(3): 452-460. (in Chinese)

Shen Y J, Liu C M, Liu M, et al. 2010. Change in pan evaporation over the past 50 years in the arid region of China. Hydrological Processes, 24(2): 225-231.

Sheng Q, Shen S H, Gu Z. 2007. Conversion coefficient between small evaporation pan and theoretically calculated water surface evaporation in China. Journal of Nanjing Institute of Meteorology, 30(4): 561-565. (in Chinese)

Su T, Feng T C, Feng G L. 2015. Evaporation variability under climate warming in five reanalyses and its association with pan 
evaporation over China. Journal of Geophysical Research: Atmospheres, 120(16): 8080-8098.

Thomas A. 2000. Spatial and temporal characteristics of potential evapotranspiration trends over China. International Journal of Climatology, 20(4): 381-396.

Van Heerwaarden C C, De Arellano J V G, Teuling A J. 2010. Land-atmosphere coupling explains the link between pan evaporation and actual evapotranspiration trends in a changing climate. Geophysical Research Letters, 37(21): L21401.

Villarreal S, Vargas R, Yepez E A, et al. 2016. Contrasting precipitation seasonality influences evapotranspiration dynamics in water-limited shrublands. Journal of Geophysical Research: Biogeosciences, 121(2): 494-508.

Wang G Q, Zhang J Y, Liu J F, et al. 2011. The sensitivity of runoff to climate change in different climatic regions in China. Advances in Water Science, 22(3): 307-314. (in Chinese)

Wang K C, Liang S L. 2008. An improved method for estimating global evapotranspiration based on satellite determination of surface net radiation, vegetation index, temperature, and soil moisture. Journal of Hydrometeorology, 9(4): 712-727.

Wang P, Yamanaka T, Qiu G Y. 2012. Causes of decreased reference evapotranspiration and pan evaporation in the Jinghe River catchment, northern China. The Environmentalist, 32(1): 1-10.

Wang Z G, Wang J B, Feng J C, et al. 2011. Trends of potential evapotranspiration in Maqu county of Gansu Province in recent 40 years. Journal of Arid Meteorology, 29(4): 488-491. (in Chinese)

Wei S L, Liu L H. 2011. Analysis of evaporation results measured by $20 \mathrm{~cm}$ diameter evaporator and E601 evaporator-hydrological station in Chongli as an example. South-to-North Water Diversion and Water Science \& Technology, 9(2): 154-156. (in Chinese)

Wei W S, Hu R J. 2009. Precipitation and climate conditions of Tianshan Mountains. Arid Land Geography, 13(1): 29-36. (in Chinese)

Wu Z H, Huang N E. 2009. Ensemble empirical mode decomposition: a noise-assisted data analysis method. Advances in Adaptive Data Analysis, 1(1): 1-41.

Xiong A Y, Liao J, Xu B. 2012. Reconstruction of a daily large-pan evaporation dataset over China. Journal of Applied Meteorology and Climatology, 51(7): 1265-1275.

Xu C Y, Gong L B, Jiang T, et al. 2006. Analysis of spatial distribution and temporal trend of reference evapotranspiration and pan evaporation in Changjiang (Yangtze River) catchment. Journal of Hydrology, 327(1-2): 81-93.

Yang H B, Yang D W. 2012. Climatic factors influencing changing pan evaporation across China from 1961 to 2001 . Journal of Hydrology, 414-415: 184-193.

Zhang F Y, Li L H, Ahmad S, et al. 2014. Using path analysis to identify the influence of climatic factors on spring peak flow dominated by snowmelt in an alpine watershed. Journal of Mountain Science, 11(4): 990-1000.

Zhang Q, Qi T Y, Li J F, et al. 2015. Spatiotemporal variations of pan evaporation in China during 1960-2005: changing patterns and causes. International Journal of Climatology, 35(6): 903-912.

Zhang S F, Hua D, Meng X J, et al. 2011. Climate change and its driving effect on the runoff in the "Three-River Headwaters" region. Acta Geographica Sinica, 66(1): 13-24. (in Chinese)

Zhang S Q, Pu Z C. 2011. Temporal and spatial variation characteristics of reference evapotranspiration in Xinjiang. Transactions of the Chinese Society of Agricultural Engineering, 27(5): 73-79. (in Chinese)

Zhang Y Q, Liu C M, Tang Y H, et al. 2007. Trends in pan evaporation and reference and actual evapotranspiration across the Tibetan Plateau. Journal of Geophysical Research: Atmospheres, 112(D12): D12110.

Zheng J, Cai H J, Wang J, et al. 2009. Path analysis of yield components and water production function of watermelon in greenhouse. Transactions of the Chinese Society of Agricultural Engineering, 25(10): 30-34. 